\title{
The Value of a Closer Look
}

\author{
Charles N. Cornell, MD
}

Received: 5 May 2017/Accepted: 5 May 2017/Published online: 30 May 2017

(C) Hospital for Special Surgery 2017

Welcome to the July 2017 issue of the HSS Journal ${ }^{\circledR}$. In it, articles are presented from a wide variety of topics that are current in the musculoskeletal field. This issue reflects the multidisciplinary mission of the HSS Journal as we continue to strive to reach the broadest audience in our field of medicine and science.

Two articles deserve special mention. In my opinion, papers which raise questions about topics that are traditional or seemingly solved have great value. In order to process the great volume of medical knowledge into practice, many assumptions are simplified and approached as dogma. Regardless of the strength of the evidence that provided a practice guideline, traditional concepts, and approaches are often incorporated and then rarely questioned. In this issue, Delpizzo and colleagues and Bockman and his coauthors provide works that provide new insight by delving deeper and raising new questions about mainstream assumptions.

Delpizzo and colleagues addressed the controversial topic of post dural puncture headache in young patients. In this paper, the topic is nicely reviewed. Overall, they found a low incidence of post-spinal headache except in 15- to 19-yearold patients where an incidence of $15 \%$ was found. This paper provides a valuable review and further insight into use of spinal anesthesia for ambulatory surgery. I believe it encourages the use of spinal anesthetic for ambulatory surgery even in the pediatric population.

Bockman and his coauthors provide an in-depth analysis of their experience using teriparatide to treat loss of bone mass due to osteoporosis. The paper provides an overview of current concepts in the field and provides the theoretical basis for the approach to care, use of teriparatide as an anabolic agent as well as bone turnover markers for monitoring response to treatment. The "Discussion" section introduces the concepts currently leading to innovative uses of combination therapies that may prove more effective than current monotherapy approaches. This is an important read for all members of our specialty.

We continue to anticipate receiving your manuscripts regarding all aspects of musculoskeletal medicine and surgery. We promise unbiased and expert peer review from our international body of reviewers. We continue to boast of a quick review process and short time to publication. We trust that you will continue to consider the HSS Journal as the best forum for publication of your work.

\section{Compliance with Ethical Standards}

Conflict of Interest: Charles N. Cornell, MD, has declared that he has no conflict of interest.

Human/Animal Rights: This article does not contain any studies with human or animal subjects performed by the any of the authors.

\section{Informed Consent: N/A}

Required Author Forms Disclosure forms provided by the authors are available with the online version of this article. 